\title{
THE VIABILITY OF PALATAL CONNECTIVE TISSUE GRAFT USING SINGLE INCISION VERSUS DE-EPITHELIALIZATION HARVESTING TECHNIQUE IN NEW ZEALAND RABBITS
}

\author{
Reham Mohamed Abdelsattar*, Sahar Mahmoud Shawkat** and Shaimaa Saieed Nasr***
}

\begin{abstract}
Aim: The aim of our work was to compare the de-epithelialization graft method with the standard single incision technique for harvesting of connective tissue grafts. The viability potential of the graft was examined histologically \& immunohistochemically and histomorphometrically.

Methodology: New Zealand rabbits were divided into 2 groups: single incision group (10 rabbits) lancet $15 \mathrm{c}$ was used to perform a pouch for harvesting the connective tissue graft, and De-epithelialization group (10 rabbits), where de-epithelization was performed using flat stone and the dimensions of the donor area were measured using a millimeter periodontal probe $3 \mathrm{~mm}$ in width and $10 \mathrm{~mm}$ in length. The harvested connective tissue graft was examined histologically and immunohistochemically for CK10 expression. The graft was analyzed by flow cytometry for necrotic cells assay. Hitsomorphometric evaluation of CK10 positive surface area was done.
\end{abstract}

Results: The study demonstrated that signficant decrease was detected in a number of necrotic cells in the de-epithelialization group as compared to the single incision group. CK10 positively reacted epithelial remnants were more in the de-epithelialization group than the single incision group, but this increase was non-significant.

Conclusion: The de-epithelialization grafting technique was found to be a simple procedure. Additionally, it showed large areas of extravasated red blood cells and more adipose tissues were obvious in the single incision group as compared to the de-epithelialization group with less technical complication during the surgery. Furthermore, it revealed less necrotic cells, less hemorrhage, and more accurate in the separation of epithelium from the connective tissue.

KEYWORDS: Connective tissue graft, epithelial remnants, necrosis, viability.

* Master Student at Faculty of Dentistry Cairo University. Teaching assistant, Faculty of Dentistry, Oral Biology Department, Modern Science and Arts University,

** PhD, Professor, Oral Biology Department, Faculty of Dentistry, Cairo University, Egypt.

*** PhD, Lecturer, Oral Medicine and Periodontology Department, Faculty of Dentistry, Fayoum University, Egypt. 


\section{INTRODUCTION}

Connective tissue grafts (CTGs) have expanded acceptance and are widely used for recession management, widening the keratinized gingiva. Additionally, it can be used in controlling the soft tissue around the implant, management of furcation, alveolar ridge deficiencies, and papillary loss management ${ }^{1}$.

The harvesting of subepithelial connective tissue grafts (SCTGs) can be achieved by different means to isolate the epithelial tissue from the connective tissue. Either by raising a full- or partial-thickness flap as the pedicle flap in which reflecting partial soft tissue and leaving the mucoperiosteum connected to the bone ${ }^{2}$. The accomplishment of SCTGs has been linked to the dual blood supply at the beneficiary site from the covering flap and the connective tissue, however, slight postoperative morbidity could occur ${ }^{3}$.

Subepithelial connective tissue graft has been considered a predictable procedure that delivers an appropriate esthetic outcome, making it a convenient choice for clinicians than the free gingival graft. Additionally, SCTG based procedure offers superior mean root coverage with the handling of the connective tissue graft ${ }^{4}$.

Different subepithelial connective tissue graft harvesting techniques were constructed in the literature ${ }^{5}$, and many modifications of the techniques to harvest SCTGs have been proposed. Each technique is slightly different from the other in the number of incisions, flap design, and technique which is widely used in several periodontal plastic surgeries ${ }^{6}$.

In 1974, Edel advocated the trap door technique through which a partial thickness trapezoidal flap was elevated using no.15 blade to make one horizontal and two vertical incisions. The trap door technique permitted to hold on to the residual palatal epithelium, thus decreasing the patient's discomfort. Therefore, healing with primary intention, more accessibility and complete wound closure was obtained. However, it was reported that; vertical incisions may endanger the blood supply ${ }^{7}$.

Lorenzana et al. recommended a modification, which is the most reasonable technique for subepithelial connective tissue graft harvesting in form of one horizontal incision that was made 2-3 $\mathrm{mm}$ apical to the gingival margin perpendicular to the bone depending on the chosen graft proportions. Through this incision, a split-thickness flap was raised by slitting parallel to the long axis of teeth then, a connective tissue along with periosteum was elevated via a small elevator. However, this modified technique has drawbacks, where the harvested graft is not predictable as the periosteum is removed. Therefore, this procedure may delay the healing process ${ }^{8}$.

Reino et al. ${ }^{9}$ suggested another single incision technique for CTG harvesting which differs from the modification proposed by Lorenzana et al. ${ }^{8}$ as it includes a full thickness flap at the donor site, conserving most of the palatal periosteum. On the donor area; one horizontal incision was made 3 millimeters apical to the gingival margin, perpendicular to the palatal tissue retaining the periosteum on the underlying bone then, 1-2 mm thick flap was reflected using a periosteal elevator. Thus, this technique allows obtaining the required graft with good healing and insignificant discomfort to the patients.

In a study by Bhatavadekar and Gharpure in order to minimize necrosis and sloughing of the flap, a controlled palatal harvest technique. The blade was used to mark one horizontal incision, $2 \mathrm{~mm}$ submarginally, covering anteriorly from the first molar then, a perpendicular L-shaped incision was made at the anterior end of the first incision. A thick splitthickness flap was elevated from the boundaries of the incision leaving behind a thin periosteum covering the palatal bone. The reflected flap was held with tissue forceps, and the graft was harvested by separating it from the raised flap, leaving a $1.5-\mathrm{mm}$ thick flap for mandatory flap healing. this controlled 
palatal technique provided satisfactory graft and flap thickness, and less possibility of leaving behind a thin flap for closure at the donor area. However, it was a technique sensitive, as there was a probability of flap perforation while obtaining the graft in cases of thin mucosa 10 .

Noteworthy, subepithelial connective tissue grafts are obtained from the deep submucosal layers which include fatty and glandular tissues. Therefore, the idea of the de-epithelialized grafts was proposed, where the graft was de-epithelialized extra orally after harvesting. This technique increased the ability to harvest CTG from a more shallow level of tissues to obtain a good quality graft ${ }^{11}$.

A de-epithelialization technique was performed using large flat stone under copious irrigation with high speed handpiece. the epithelium was removed uniformly and the connective tissue graft was incised from the donor area; leaving the periosteum and a connective tissue layer above the bone, thus avoiding bone exposure which will reduce the pain and the healing time. Then, the visualization of a homogenous and bleeding surface, indicating total removal of the epithelium. ${ }^{12,13}$

Regarding the disadvantage of the de-epithelialization technique, where there could be remnants of epithelium residing in different proportions in the graft. However, the epithelium did not appear to affect the experimental results ${ }^{14}$.

Most literatures handled with the extra oral deepithelialization technique from the clinical point of view. They investigated the feasibility of this method in harvesting regarding thickness of the harvested tissues, time consuming, damage of tissue by trauma, and healing of the donor site. However, very few papers discussed the histologic picture of the intra oral de-epithelialization technique. Therefore, this study was conducted to assess the presence of viability of connective tissue epithelial remnants and using single incision versus deepithelialization technique.

\section{MATERIALS AND METHODS}

\section{Ethical statement}

This research was conducted in the Animal Research center faculty of medicine, Cairo University, Egypt according to the recommendations and approval of the ethics committee (IACUC) (approval no.CU-III-F-71-18) on animal's experimentation of the Faculty of Medicine, Cairo University.

\section{Experimental Animals}

- Twenty-three adult male New Zealand rabbits were used in this study with an age range from 7 to 8 months and weight range from 2500 to 3000 g. The rabbits were obtained from the animal house, Faculty of Medicine, Cairo University.

- They were housed into a sterile, controlled environment (temperature $25 \pm 2^{\circ}$ and $12 \mathrm{hrs}$. dark/light cycles) and fed with a standard pellet diet and tap water adlibitum. They were kept in individual cages. All groups were kept under the same housing and feeding conditions.

\section{Experimental design}

\section{Sample size}

- The sample size was calculated using the (G power software) t-test. As regarding the primary outcome (viability of connective tissue graft), we found that selecting 10 rabbits per experimental group was an appropriate sample size for the study with a total sample size of 20 rabbits (2 groups)

Extra three rabbits were considered as negative control. The animals were anesthetized and sedated as the experimental animals. A full epithelium and connective tissue graft were harvested from them. These grafts were H\&E stained routinely. 


\section{Randomization and Allocation Concealment}

- The rabbits were randomly distributed by the Random Sequence Generator program (random. org.). Implementation of the allocation was done as follow:

- Numbers from 1 to 23 were written on foursided folded papers that were placed in opaque sealed envelopes.

Matching the rabbits with the numbers was done blindly through the technician in charge at the animal house.

- Each rabbit was attached to its number till the end, then the numbers were opened and the rabbits were allocated in their groups according to the program recommendations.

- Blinding during the assessment: All the histological experimental sections were examined in a masked fashion by two separate observers and scored. The scores were given by the observers for each histological section were averaged and used in data analysis.

\section{Experimental Endpoint}

At each experimental endpoint, the single incision group animals, the reflected flap was sutured back with interrupted suture using $5 / 0$ absorbable suture material ${ }^{15}$. Regarding, the de-epithelialized group a hemostatic gauze was placed on the palatal wound, immersed with vitamin $\mathrm{K}$ to stop any bleeding, and finger pressure was applied until complete hemostasis was attained. Then, analgesia was given via the drinking water (100 mg metamizole per $\mathrm{kg}$ body weight each $24 \mathrm{~h})^{16,17}$.

\section{Animal grouping}

The experimental animals were divided into two groups:

Group I: The single-incision 10 rabbits were included.

Group II: The de-epithelialization 10 rabbits were included.
TABLE (1): Illustrates the complexity of the study design

\begin{tabular}{ccc}
\hline & $\begin{array}{c}\text { Group I (Single- } \\
\text { incision GP) }\end{array}$ & $\begin{array}{c}\text { Group II (De- } \\
\text { epithelialized GP) }\end{array}$ \\
\hline No. of rabbits & 10 & 10 \\
\hline Intervention & Single-incision & De-epithelialization \\
\hline Route & Lancet (15c) & flat stone (2mm thickness) \\
\hline
\end{tabular}

\section{Experimental procedures}

\section{Single incision procedure}

- First, all animals were deeply anesthetized by intravenous injection of $50 \mathrm{mg} / \mathrm{kg}$ of ketamine HCL and sedated by xylazine $2 \%$.

- The dimensions of the donor area were measured using a periodontal probe, $3 \mathrm{~mm}$ in length 10 $\mathrm{mm}$ as shown in Figure (1A) and $3 \mathrm{~mm}$ in width as shown in Figure $(1 \mathrm{~B})^{12}$.

- Then, according to Hürzeler ${ }^{18}$ a \#15C scalpel blade was used to make a single horizontal incision in the existing edentulous area between the 1st molar and the incisors deep down to the bone $2 \mathrm{~mm}$ from the gingival margin. The angle of the blade was $90^{\circ}$ to the bone. Then, undermining to the pouch was performed to separate the overlying epithelium.

- With each new movement of the scalpel along the incision line, the angle was further flattened until the blade reaches a nearly parallel position to the bone surface.

- The underlying CTG was separated from the surrounding connective tissue by making incisions to the bone on the mesial, distal, and medial sides of the graft.

- The graft was then removed by separating it from the bony surface with a periosteal elevator.

\section{De-epithelialization procedure}

A large size $2 \mathrm{~mm}$ flat stone under copious irrigation was utilized after marking the extension 
of the graft as mentioned before, to de-epithelialized the graft with careful handling and ensure that the epithelium was removed uniformly. The visualization of a homogenous and bleeding surface was indicating total removal of the epithelium. When the connective tissue appeared in regions, the graft was incised with the aid of a No. 11 blade and removed from the donor area ${ }^{12}$.

\section{Methods of investigation}

\section{Hematoxylin and Eosin for histological evalu- ation:}

Histological examination Hematoxylin and Eosin (H\&E) stain following the standard technique was carried out to assess the histologic picture of the connective tissue graft ${ }^{19}$.

\section{Immunohistochemical procedures}

To measure the expression of Cytokeratin 10 (CK10) in epithelial remnants;

\section{Dako EnVision FLEX visualization systems was used}

After the graft was excised, it was fixed immediately in $10 \%$ neutral buffered formalin. The specimens were processed routinely. The embedded specimens were sectioned by microtome 4 microns thick. The sections were seated on clean positively charged glass slides and were subjected to immunohistochemical reaction .

\section{Immunohistochemical interpretation}

Positive expression of cytokeratin 10 was demonstrated as brown discoloration of the nucleus, membrane, and cytoplasm.

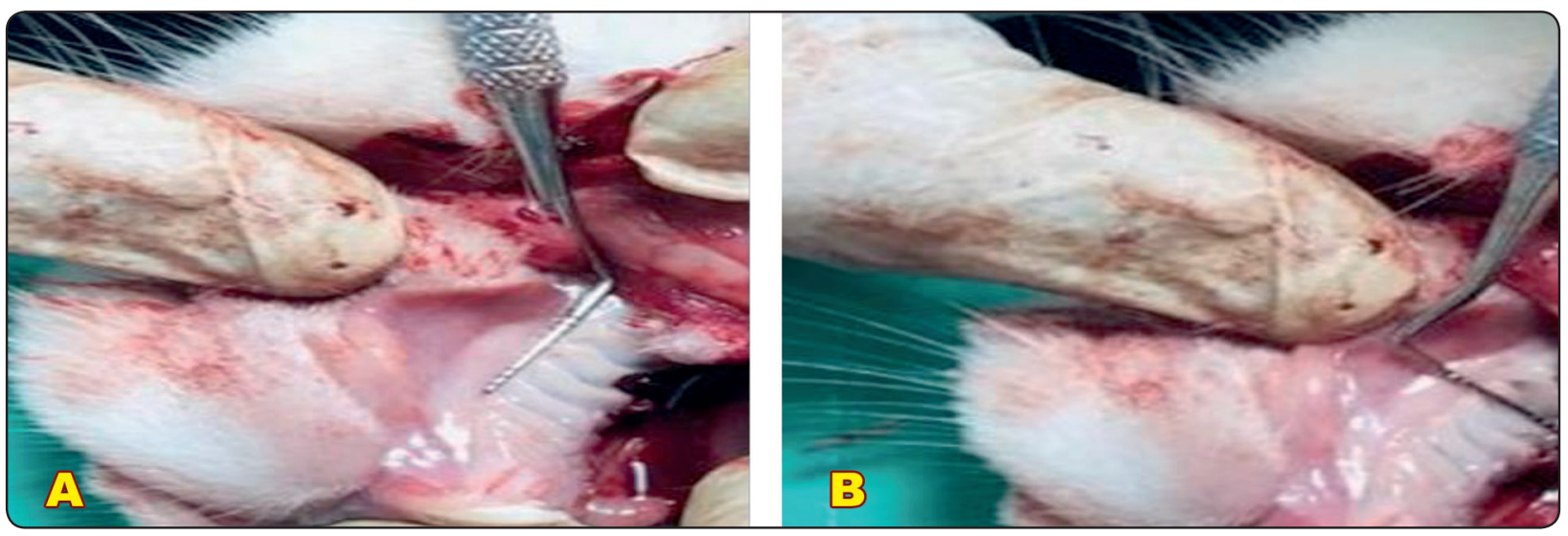

Fig. (1) (A) measuring the graft length (B) measuring the graft width

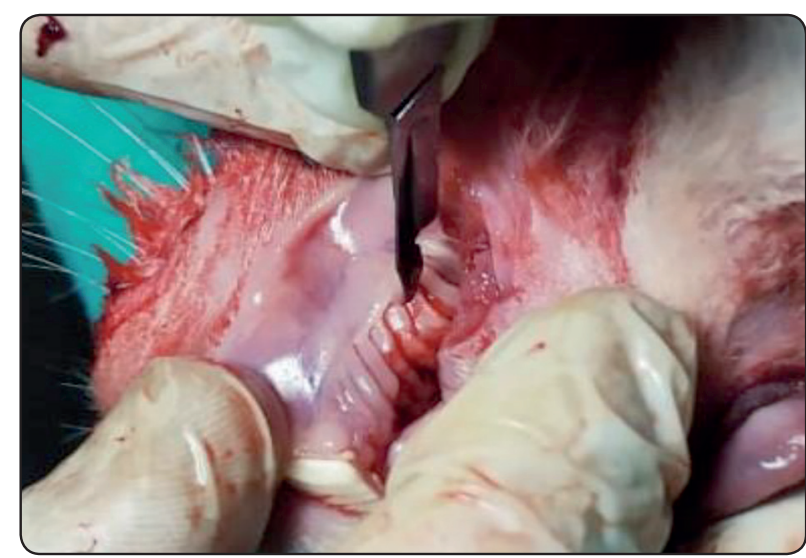

Fig. (2) Single incision technique using 15c blade

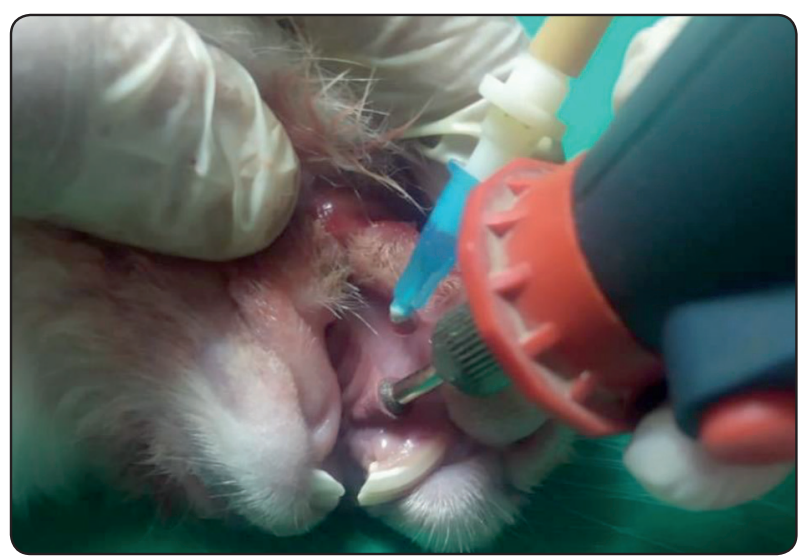

Fig. (3) De-epithelialization technique using the flat stone 


\section{Histomorphometric analysis (Quantitative assessment of Cytokeratin 10)}

The epithelial remnants were evaluated in terms of the area/percentage. This was performed by an image analyzer system using the software Leica Quine 500(Leica Microsystems, Switzerland), Oral Pathology Department, Faculty of Dentistry, Cairo University. The image analyzer consisted of a colored video camera, colored monitor, and a hard disc of IBM personal computer connected to a microscope Figure (5). To determine the area of epithelial remnants of epithelium/ field, the positively reacted epithelial cells were measured in each field. For each group, 5 representative photographs were taken.

\section{Flow cytometry analysis for Necrotic cell assay}

Passage 1 cells were trypsinized, washed, and resuspended in PBS at a concentration of $1 \times 106 / \mathrm{ml}$. The cells were stained for 20 minutes in the dark with monoclonal antibodies conjugated with fluorescein isothiocyanate (FITC) and phycoerythrin (PE).7amino-actinomycin D (7 AAD-Sigma Aldrich) was added for 20 minutes in all tubes to ensure gating on viable cells. 10,000 cells were analyzed by CYTOMICS FC 500 flow cytometer (Beckman Coulter, FL, USA) using CXP Software version 2.2.

\section{Statistical analysis}

For binary outcomes effect size was measured using Relative risk (RR) $95 \%$ confidence interval(CI) The data obtained from the histomorphometric analysis were statistically described in terms of mean value +or - standard deviation (SD) F-test (One way ANOVA) test was used to make a comparison between the studied groups with the Conover Inman test for independent samples as post hoc multiple 2-group comparisons. P-value $<0.05$ was considered statistically significant. For statistical analysis, the statistical package for social science (SPSS) software version 17 was used.

\section{RESULTS}

\section{I- Histological results}

The negative control specimens showed that the rabbit palatal mucosa consisted of epithelium, lamina propria, and basement membrane. The covering epithelium is para-keratinized stratified squamous epithelium consisting of approximately 10-14 layers of keratinocytes. The epithelial ridges were numerous and irregular. The lamina propria was formed of a papillary layer and reticular layer consisting of collagen fiber bundles, blood vessels, and some dispersed inflammatory cells. Some epithelial niches were demonstrated in the lamina propria as a result of the plane of section. A well-defined submucosa was evident. It is formed of collagen bundles, cells, blood vessels, and adipose tissue.

\section{Single incision group: (group I)}

The histological examination of the palatal CTG harvested by the single incision method revealed the following:

The samples were composed of dense connective tissue with dense collagen fiber bundles, blood vessels, and adipose tissue in the submucosa.

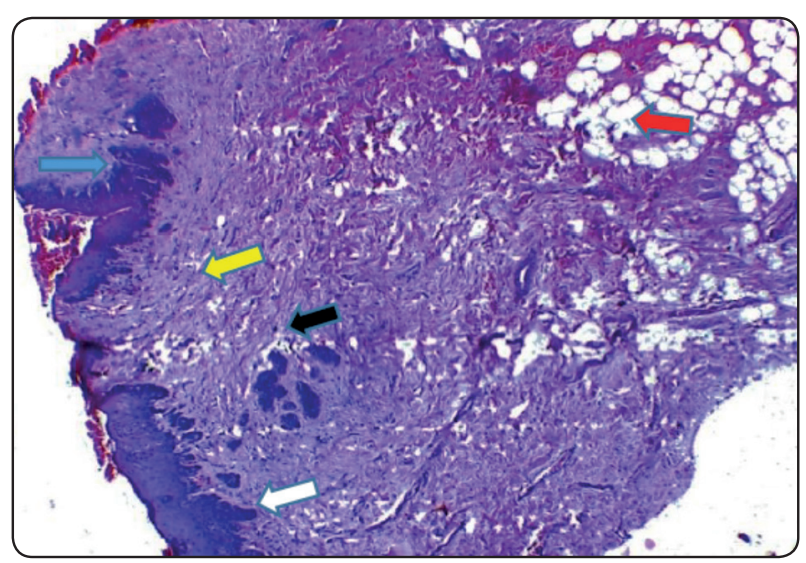

Fig. (4) A photomicrograph of New Zealand palatal mucosa showing collagen fibers (yellow arrow), epithelial ridges (white arrow), dispersed inflammatory cells (black arrow), fat cells (red arrow), and some epithelial niches (blue arrow) (H\& E x40) 
High amounts of adipose tissue and low amounts of dense connective tissue were observed in almost all samples. Large dilated blood vessels were found in all samples as well as some scattered inflammatory cells infiltrate.

Large areas of hemorrhage (extravasated red blood corpuscles) on the surface as well as embedded inside the connective tissue itself were noticed in all samples Fig. (5). Some samples showed the presence of remnants of the epithelial rete pegs over the lamina propria layer (Fig.6).

\section{De-epithelialization group (group II)}

The histological examination of the palatal CTG of the New Zealand rabbits following the harvesting using the de-epithelialization technique revealed the presence of a dense core of connective tissue composed of collagen fibers, cells, adipose tissue, and blood vessels.

The collagen fiber bundles appeared wellorganized parallel to the surface and embedded in amorphous extracellular ground substance. The

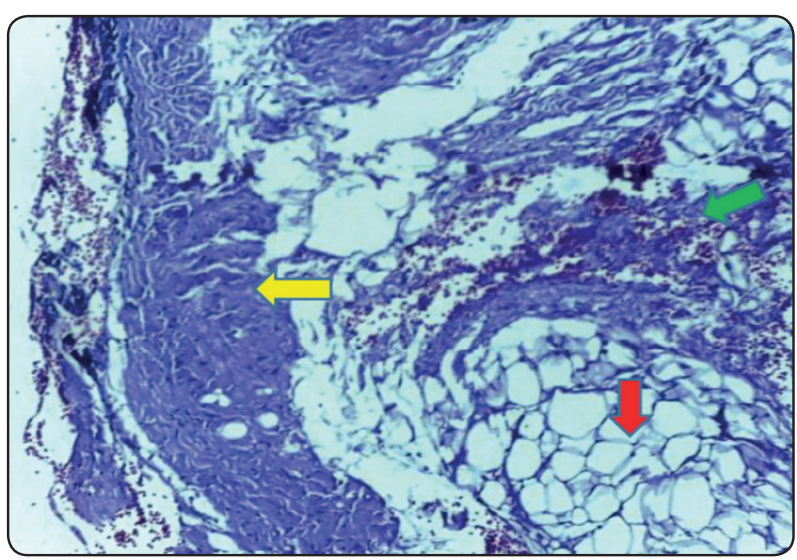

Fig. (5) A photomicrograph of the palatal connective tissue Graft in single incision technique showing abundant collagen Fibers (yellow arrow) and fat cells (red arrow) extravasated RBCs (green arrow) (H\& E x40). specimens showed few scattered inflammatory cells infiltrate and blood capillaries. Fewer amounts of adipose tissues as compared with group I were also noted (Fig.7, 8).

Some small areas of hemorrhage were evident in some of the specimens mainly on the surface of the connective tissue graft. Some samples exhibited the presence of parts of epithelial ridges on the surface of the graft (Fig.8).

\section{II- Immunohistochemical detection of cytokera- tin 10 (CK10)}

\section{1- Single incision group:}

On examining the immunohistochemical reaction of CK10, palatal CTG of New Zealand rabbits harvested by the single incision method revealed that two of the 10 samples showed the presence of positively reacted remnants of the epithelial rete pegs over the lamina propria layer. (Fig. 9) The rest of the samples showed a negative reaction of all the elements forming the graft (Fig. 10).

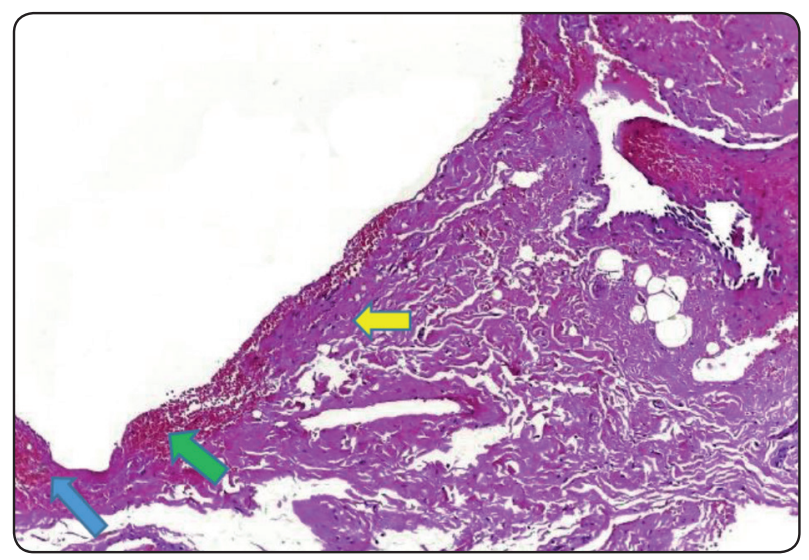

Fig. (6) A photomicrograph of another slide in a single incision technique showing rete pegs (blue arrow), areas of hemorrhage (green arrow) and fibers (yellow arrow) (H\& E x40) 


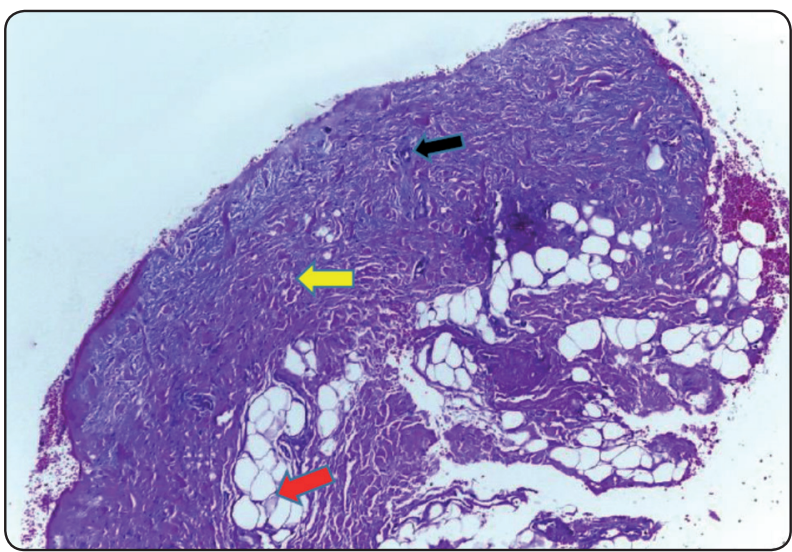

Fig. (7): A photomicrograph of palatal graft in deepithelialization technique showing thick collagen fibers (yellow arrows), few inflammatory cells (black arrow) and fat cells (red arrow) (H\& E x 40).

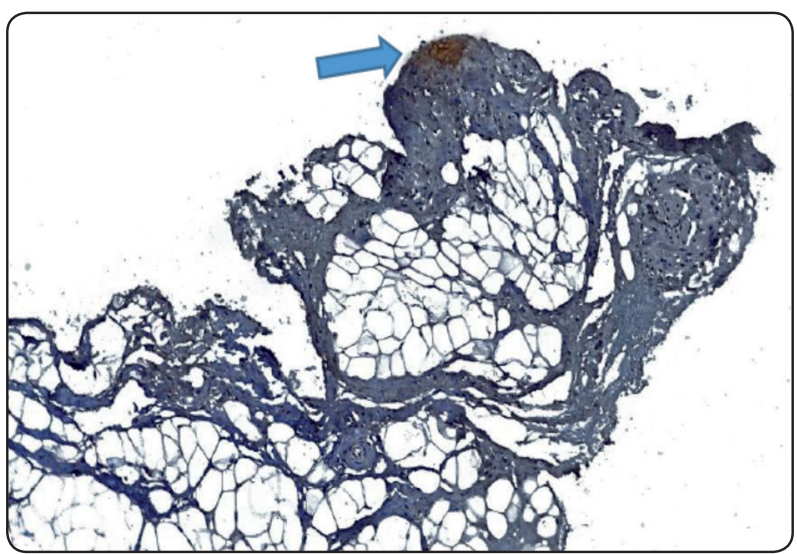

Fig. (9) A photomicrograph of palatal connective tissue graft following single incision technique showing the positive reaction of the epithelial remnants over the lamina propria surface (blue arrow) (DAB x40).

\section{2-De-epithelialization group}

Immunohistochemical examination of the palatal CTG of the de-epithelialization group revealed CK10 positively reacted cells in four out of the 10 examined samples. This CK10 expression was detected in parts of epithelial rete pegs over the lamina propria surface (Fig.11) as well as separate positive islands between the superficial layers of graft lamina propria (Fig.12). The other samples revealed a negative reaction for CK10 in all forming elements (Fig.13).

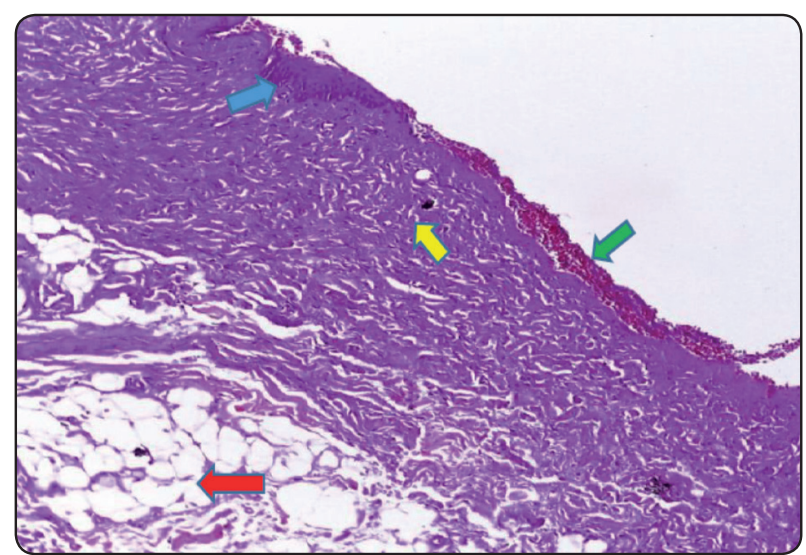

Fig. (8) A photomicrograph of another slide of deepithelialization technique showing remnants of rete pegs (blue arrow), connective tissue fibers (yellow arrow), fat cells (red arrow), and little hemorrhage (green arrow) (H\& E x40).

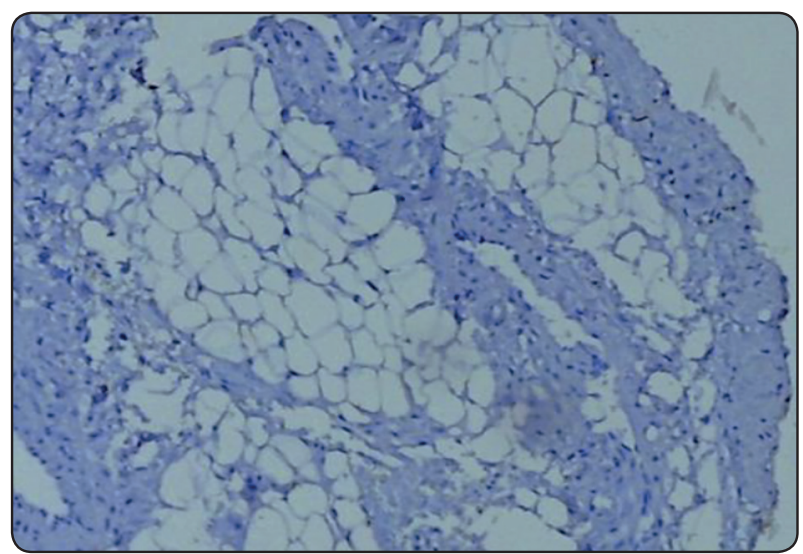

Fig. (10): A photomicrograph of connective tissue graft following single incision procedure showing negative staining reaction of all the graft components (DAB x100).

\section{III- Area percentage}

Group I was associated with area percent of CK10 immune-expression $\mathrm{M}=2.29(\mathrm{SD}=0.65)$. By comparison, group II was associated with numerically larger area percent of CK10 immuneexpression $\mathrm{M}=2.63$ ( $\mathrm{SD}=0.91$ ). To test the hypothesis that group I and group II were associated with a statistically significant difference of their means, an independent t-test was performed. Additionally, the assumption of homogeneity of variance was tested 
via Levene's test, $\mathrm{F}=1.76, \mathrm{P}=0.2$. Independent t-test revealed no significant difference between group I and group II. A graphical presentation of the means difference was shown in Fig. (15).

\section{IV- Flow cytometry Analysis}

Using flow cytometric analysis, the expression of non -viable cells was measured in percentage between the single incision group and the deepithelialization group Flow cytometry confirmed the percentage was significantly increased in the single incision group; equals to $10.9 \%$. In the deepithelialization group, percentage of non- viable cells was $2.96 \%$.

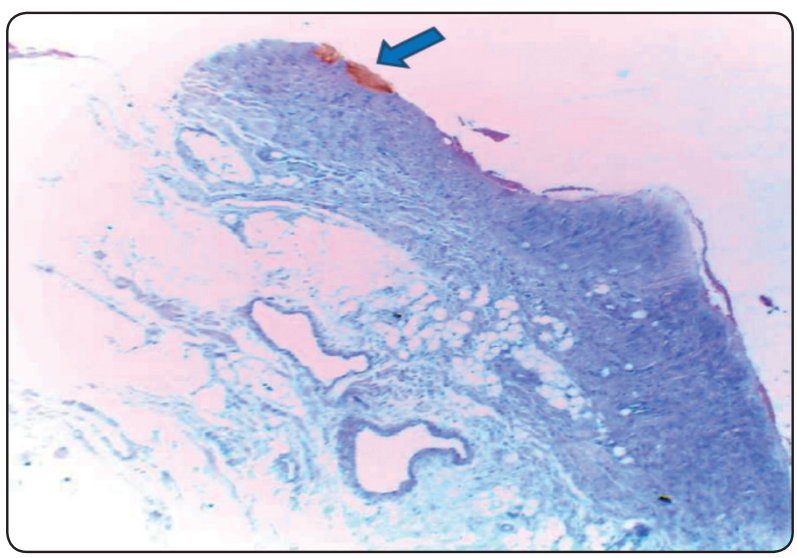

Fig. (11): A photomicrograph of connective tissue graft following de- epithelialization technique revealing a positive reaction of the epithelial rete pegs over the surface of lamina propria (blue arrow) (DAB, x40).

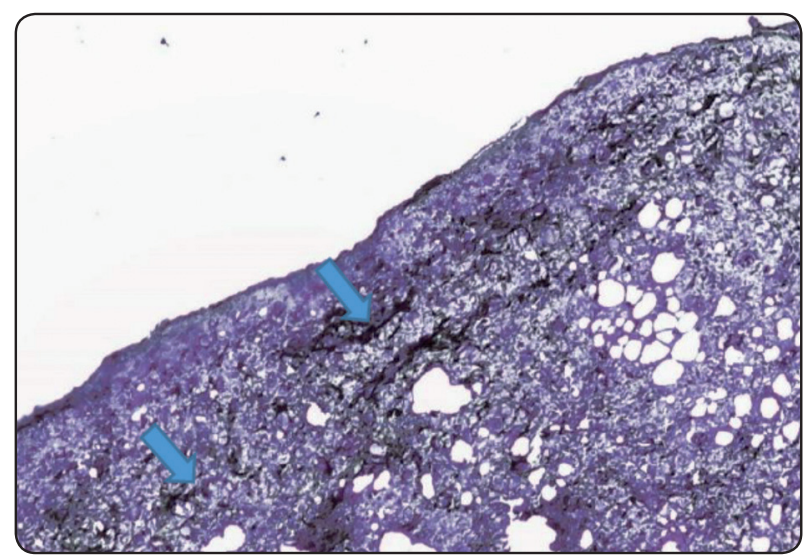

Fig. (12) A photomicrograph of palatal connective tissue graft following de- epithelialization technique showing separate positive islands of epithelium between the superficial layer of the lamina propria (blue arrow) (DAB, $\mathrm{x} 40)$.

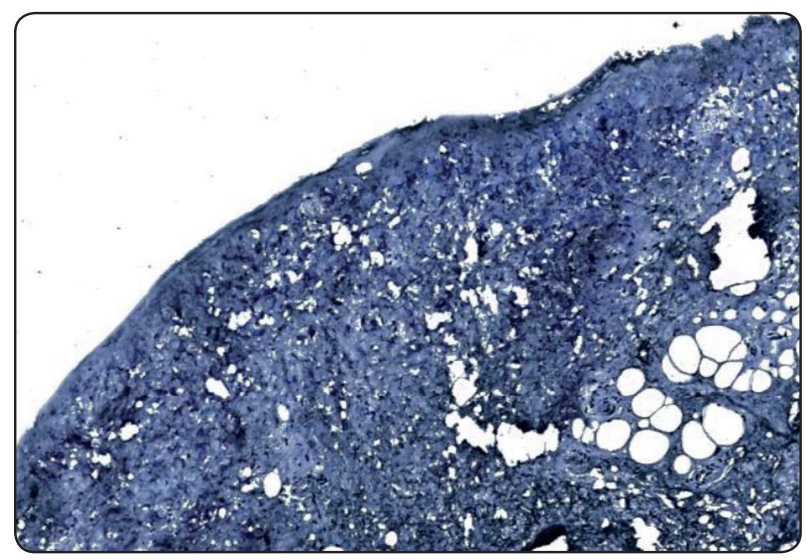

Fig. (13) A photomicrograph of connective tissue graft following de-epithelialization procedure showing negative staining reaction of all the graft components (DAB x40).

TABLE (2): Comparison of number of non-viable cells between studied groups

\begin{tabular}{|c|c|c|c|c|c|c|c|c|}
\hline & \multirow{2}{*}{$\mathrm{N}$} & \multirow{2}{*}{ Mean } & \multirow{2}{*}{$\begin{array}{c}\text { Std. } \\
\text { Deviation }\end{array}$} & \multicolumn{2}{|c|}{$\begin{array}{l}95 \% \text { Confidence } \\
\text { Interval for Mean }\end{array}$} & \multirow{2}{*}{ Minimum } & \multirow{2}{*}{ Maximum } & \multirow{2}{*}{$\begin{array}{c}\mathrm{P} \\
\text { value }\end{array}$} \\
\hline & & & & Lower Bound & Upper Bound & & & \\
\hline Group I & 10 & 7.75 & 1.85 & 6.43 & 9.08 & 4.18 & 10.90 & \\
\hline Group II & 10 & 4.39 & 0.77 & 3.83 & 4.95 & 2.96 & 5.71 & $<0.001$ \\
\hline
\end{tabular}

Data were expressed as mean $\pm S D$. p-value $<0.05$ is considered significant. Significant decrease in the number of nonviable cells in the de-epithelization group compared to single incision group ( $p$-value $<0.001$ ). Data were coded and entered using the statistical package SPSS version 22. Data were statistically described in terms of mean, standard deviation minimum, maximum. An unpaired t-test was used to compare non-viable cells between the studied groups. A probability value (P-value) less than 0.05 was considered statistically significant ${ }^{20 .}$ 


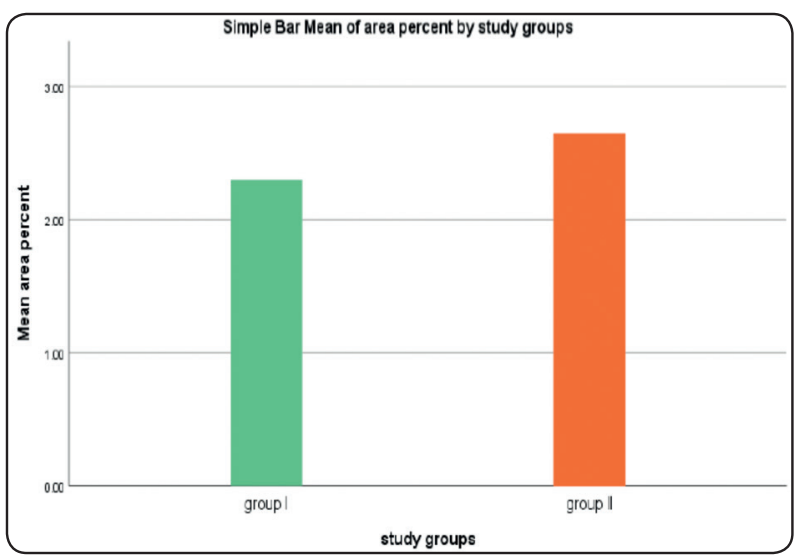

Fig. (14) Bar chart representing mean and standard deviation values for expression of cytokeratin 10 in the two groups.

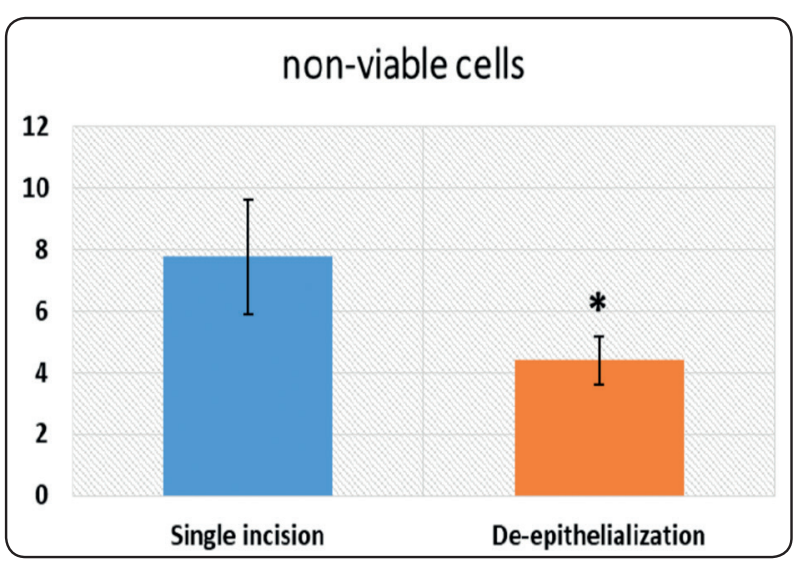

Fig. (15) Bar chart representing mean and standard deviation values for percentage of non -viable cells between the two groups

\section{DISCUSSION}

The advent of esthetic dentistry has led to increased use of soft tissue graft obtained from the hard palate for periodontal regenerative surgeries to treat gingival recession. Two types of autografts are commonly harvested from the palate: the free gingival graft and the connective tissue graft. The connective tissue graft is often the first choice over the free gingival graft due to its superior esthetic result and a high potential for primary healing at the donor site. So, harvesting good quality connective tissue grafts is important in regenerative surgeries.
Different connective tissue graft harvesting techniques were described in the literature. Subepithelial connective tissue graft (SCTG) which was introduced by Langer and Langer is termed sub-epithelial as the connective tissue for the graft is harvested without the superficial epithelium ${ }^{21}$. This technique was modified by Harris then, it was indicated in most of the periodontal procedures 22. The objective of this technique was to improve the predictability of root coverage and it had the advantage of the dual blood supply from the graft and the overlying flap Chambrone et al. ${ }^{23}$. But the main drawback of the SCTG is that it had the risk of inducing damage to the greater palatine nerves and vessels as the harvesting went deep down to the bone. In addition, donor site morbidity, excessive bleeding, and prolonged pain/discomfort were reported by Petrungaro et al. ${ }^{24}$.

Therefore, the concept of the de-epithelialized grafts began to develop as it was concluded that the preferable method to increase the amount of lamina propria of the graft is obtaining more shallow grafts ${ }^{25}$. Zucchelli et al. confirmed that the de-epithelialized graft can be carried out as the connective tissue graft consists of collagenrich connective tissue from lamina propria of the palatal mucosa, even in the presence of thin palatal tissues. This approach deals with the most superficial portion of the connective tissue, which is denser and firmer than that closer to the palatal bone and this may restrict the volumetric contraction of the connective tissue graft. The de-epithelialized technique is recommended in case of insufficient connective tissue of the palatal mucosa whereas the single incision is contraindicated because a $2 \mathrm{~mm}$ of soft tissue thickness should be left covering the palatal bone and the flap also should contain both epithelium and connective tissue for its viability and to avoid necrosis of the palatal flap ${ }^{11}$.

Noteworthy, Lim et al. supported that the connective tissue layer with the periosteum could be left above the donor site bone, thus avoiding bone exposure. This can considerably reduce the 
pain caused by bone exposure at the donor site and reduce the healing period. Therefore, the connective tissue of suitable thickness could be acquired even from a thin palatal tissue. The present study was performed to compare between the standard single incision CTG technique and de-epithelialization grafting technique in terms of the viability of connective tissue graft ${ }^{13}$.

In our study we chose New Zealand rabbits as study models, as they have a good ability to resist surgical trauma, avoiding most of the severe postoperative complications and leading to a better survival rate ${ }^{26,27}$. Females rabbits were excluded to avoid any hormonal disturbance that may affect the data due to the estrous cycle ${ }^{28}$. The area of choice was the palatal masticatory mucosa. It was reported that the masticatory mucosa exhibits distinct resistance to distortion under load, which comprises a surface epithelial layer and a deeper connective tissue layer ${ }^{29}$.

In the present work, the best surgical procedures were only done after administration of intramuscular xylazine sedation which kept the animal sedated for a longer time with minimal pain. Xylazine has a wide margin of safety. Moreover, increasing the dose does not usually increase the degree of sedation but rather the duration of effect ${ }^{26}$. The surgery was done after the general anesthesia was given to eliminate the pain then, a palatal incision was made using a \#15C scalpel blade to make a single horizontal incision in the existing edentulous area between the 1st molar and the incisors as \#15C blade gives more accessibility, more delicate with better cutting and avoids tearing of soft tissue ${ }^{31}$. The bevel on the \#15C blade is $1 \mathrm{~mm}$ and could be used as a guide to making sure that enough tissue was taken. At the experimental endpoint, we used absorbable suture material which breaks down by the body and to adapt, stabilizes the flap, and closes the wound on the donor area as recommended by

\section{Lorenzana et al. ${ }^{8}$}

In the current study, we selected the single incision technique as a comparator. It was reported that this technique provided a graft with less donor morbidity ${ }^{18}$. Furthermore, Fickel et al compared the single incision technique with the trap door approach and they stated that patient morbidity was less after harvesting with the single incision technique due to the improved remaining blood supply of the flap ${ }^{31}$. Besides, the single incision approach was reported to be applicable for different anatomic variations of the palate and healing by primary intention. The authors concluded that the main shortcoming of this procedure was the reduced visibility and controlling the graft thickness as the incision went down deep to the bone. These findings come in accordance with our procedures as we faced decreased visibility during the experimental procedures resulting from the excessive bleeding during graft harvesting via single incision technique, as the periosteum was included in the graft.

This was in accordance with the findings of a study, where it was proposed that the de-epithelialization technique that kept the periosteum intact result in less bleeding. The authors concluded that the de-epithelialization technique in harvesting the connective tissue graft avoids the damage of the blood vessels, permits graft with less amount of adipose and glandular tissues of the submucosa ${ }^{32}$.

Therefore, the concept of de-epithelialized graft technique allowed obtaining a shallower graft containing more fibrous and less fatty connective tissue with adequate quality and quantity. Additionally, the connective tissue graft that was removed with this technique does not deeply invade the palatal submucosa, unlike the other technique that required deeper dissection. According to Mcleod et al., this would lead to less palatal morbidity. Accordingly, the current study was performed to compare the single incision technique versus de-epithelialization technique for graft harvesting ${ }^{16}$.

Regarding the palatal graft viability potential was examined histologically using hematoxylin 
and eosin to investigate the histological picture of the graft and spot-on any changes occurring in it. It is considered the principle stain in histology in particular because it can be done quickly and stains tissues in such a way that a considerable amount of microscopic anatomy is revealed, and can be used to diagnose a wide range of histopathologic conditions $^{33}$. A negative control sample of the rabbit was used to spot any changes in the graft tissues, and considered as a benchmark for detection of any deviation from it.

Further histological evaluation was done using quantitative histomorphometric analysis of the immunohistochemical expression of CK10. Hematoxylin and eosin were not accurate to detect the remnants found between the lamina propria; therefore, we used CK10 to accurately localize any epithelial remnant present in the graft. The positively reacted epithelial remnants were morphometrically analyzed using the area percentage parameter. CK10 was selected in the present study to detect the presence of epithelial remnants in the graft tissue as it was reported before being intensely expressed in the normal hard palate, gingival keratinized tissue, and negatively expressed in the non-keratinized buccal mucosa. Additionally, it was expressed in the epithelium of tuberosity and hard palate keratinized tissues ${ }^{34}$.

Histological examination of both groups revealed an amount of adipose tissues in the submucosa. The fatty cells appeared more in the single incision group than the de-epithelialization group. This finding coincides with the results of Azar et al. where it was concluded that the adipose tissue obtained with the de-epithelialized technique was minimal, as adipose tissue may hinder the revascularization of the graft and impair the root coverage procedure. Moreover, there was less cellular component with larger blood vessels in deeper connective tissue than on the surface ${ }^{35}$.

Zucchelli concluded that the de-epithelialization of the graft with the diamond drill was believed more problematic surgically and biologically due to surface bleeding and difficult visualization ${ }^{36}$. In ad- dition, it was reported that superficial tissue necrosis may happen when rotating instruments are used, harming the vascular exchange between the connective tissue and the flap. However, in the present study this problem was not observed as the bleeding was less than the single incision group, this was in agreement with de Mattos et al. \& Lim et al. ${ }^{12,13}$.

Moreover, another type of drill was used (a flat stone with $2 \mathrm{~mm}$ thickness) with copious irrigation created an easy visualization of the operative scope and allowed greater regularity in epithelial removal. Noteworthy, a flat stone was used instead of a bur as the rabbit's palate possesses many corrugations that may get stuck into the cutting blades of the bur. The demarcated area was de-epithelialized using a flat stone with micro motor handpiece until the epithelium was removed, which was clinically determined by the appearance of pinpoint bleeding from the capillary loops of the connective tissue bed.

Hence, de-epithelializing graft on the palate is easy to accomplish because it is tightly bound to the underlying structures. Even in the case of loose palatal tissue, the injection of anesthetic solution can create more rigidity and resistance, thus facilitating the epithelium removal. When using this method, it is important to maintain a thickness of $1 \mathrm{~mm}$ to reduce the risk of compromising the neurovascular bundle and the degree of secondary healing ${ }^{16}$

The histological results of both groups of the present study showed that the graft is formed of dense connective tissue. Epithelial remnants in the form of rete pegs ends were evident in 2 out of 10 samples in the single incision group. On the other hand, epithelial remnants of the rete pegs appeared in 4 out of 10 samples of the de-epithelialization group. These results somewhat vary from the de Mattos et al. results who detected epithelial remnants in 2 out of 10 samples in the de-epithelialized group ${ }^{12}$. This variation may be due to different experimental models as the authors conducted their research on human palatal mucosa as well as the different tool for de-epithelialization. 
When the histomorphometric analysis of CK10 positively reacted cells in both groups was done, the de-epithelialization group was associated with a numerically larger area percent of CK10 immuno expression than the single incision group. However, when this is statistically analyzed the increase was non -significant as compared to the single incision group. Several studies have suggested that the presence of an epithelial remnant may have an expressive clinical effect because it possibly results in the formation of cysts ${ }^{38}$. This finding correlate with a histologic study concerning the subepithelial connective tissue graft technique ${ }^{25}$. However, many authors have assessed the presence of epithelial remnants (and even the existence of all the epithelial tissue) in SCTGs and reported that there were no clinical dissimilarities ${ }^{38}$.

On the other hand, the necrotic non- viable cells content of the graft was analyzed using flow cytometry and the results were analyzed statistically. Detecting the percentage of the necrotic cells by flow cytometry is considered an accurate tool as mentioned by Ciftci et al., where the necrotic and apoptotic effects of silver nanoparticles were examined on human adenocarcinoma cells ${ }^{39}$. The data in the current study were expressed as mean \pm SD. p-value $<0.05$ is considered significant. The statistical results showed a significant decrease in number of non-viable cells in the de-epithelialization group compared to single incision group (p-value $<0.001)$. The decrease in number of necrotic cells in the de-epithelialization group may be due to the trauma directed to the graft was much less in comparison to the single incision group. Chaushu et al. described the single incision technique as a traumatic procedure ${ }^{15}$.

Most probably the single incision technique showed more hemorrhage and necrosis because the deeper incision in this technique causes more cutting to the blood vessels and trauma. Therefore, reduced visibility which lengthens the harvesting time, leads to an increased number of necrotic cells that were anticipated. This finding comes in agreement with Kumar et al. where it was advocated that the incision incises the connective tissue through and through, and the blood vessels in the connective tissue causing bleeding and reduced visibility ${ }^{30}$.

As regards the present work, the uncontrolled thickness was obvious in all samples of the single incision group and submucosa was clearly seen in most samples of this group. Additionally, more adipose tissue was obvious in the single incision group specimens than the de-epithelialization group. These findings coincide with that of Azar et al. who reported the presence of residual fatty tissues in some of their specimens of harvesting connective tissue graft ${ }^{35}$.

These findings correlate with Bertl et al where the single incision technique was compared to the de-epithelialized graft technique and explained that the fatty tissue found in the harvested graft would exhibit larger shrinkage and may be more easily compressed by the overlying flap compared to grafts that consist largely of fibrous connective tissue ${ }^{40}$. In contrast, a histological study that evaluated the subepithelial connective grafts, stated that all the grafts worked well clinically even if they contained submucosa with adipose tissue ${ }^{25}$.

\section{CONCLUSION}

1. The single incision technique showed uneven graft thickness, more hemorrhage, more necrotic cells, and more adipose tissue than the de-epithelialization technique.

2. De-epithelialization technique could be used in most periodontal surgeries, as it is much easier, with less complications, and gives a more uniform thickness of the graft.

3. De-epithelialization technique revealed less hemorrhage and more accuracy in the separation of epithelium from the connective tissue.

4. Epithelial remnants could be demonstrated in the specimens of both groups. 


\section{REFERENCES}

1. Puri, Komal, Ashish Kumar, Manish Khatri, Mansi Bansal, Mohd Rehan, and Srinivasa Tenkasale Siddeshappa (2019) "44-year journey of palatal connective tissue graft harvest: A narrative review. J Indian Soc Periodontol, 23, no. 5395.

2. Bosco, A. F., \& Bosco, J. M. D. (2007). An Alternative Technique to the Harvesting of a Connective Tissue Graft from a Thin Palate: Enhanced Wound Healing.J. Periodontol, 27(2).

3. Reddy, P. K., Bolla, V., Koppolu, P., \& Srujan, P. (2015). Long palatal connective tissue rolled pedicle graft with demineralized freeze-dried bone allograft plus platelet-rich fibrin combination: A novel technique for ridge augmentation-Three case reports. J Indian Soc Periodontol, 19(2), 227.

4. Chambrone, L., \& Tatakis, D. N. (2015). Periodontal soft tissue root coverage procedures: a systematic review from the AAP Regeneration Workshop. J.periodontol, 86, S8-S51 .

5. Chambrone, L., Pannuti, C. M., Tu, Y. K., \& Chambrone, L. A. (2012). Evidence-based periodontal plastic surgery. II. An individual data meta-analysis for evaluating factors in achieving complete root coverage. J.periodontol, 83(4), 477-490.

6. Chiu, T. S., Chou, H. C., Kuo, P. J., Liang, J. Y., \& Chiu, H. C. (2020). A novel design of palatal stent to reduce donor site morbidity in periodontal plastic surgery. J. Dent. Sci.

7. Edel, A. (1974). Clinical evaluation of free connective tissue grafts used to increase the width of keratinised gingiva. J.Periodontol, 1(4), 185-196.

8. Lorenzana, E. R., \& Allen, E. P. (2000). The single-incision palatal harvest technique: a strategy for esthetics and patient comfort. Int J Periodontics Restorative Dent, 20(3), 297-306.

9. Reino, D. M., Novaes Jr, A. B., Grisi, M. F. D. M., Maia, L. P., \& Souza, S. L. S. D. (2013). Palatal harvesting technique modification for better control of the connective tissue graft dimensions. Braz Dent J, 24(6), 565-568.

10. Bhatavadekar, N. B., \& Gharpure, A. S. (2018). Controlled Palatal Harvest (CPH) Technique for Harvesting a Palatal Subepithelial Connective Tissue Graft. Compendium.

11. Zucchelli, G., Mele, M., Stefanini, M., Mazzotti, C., Marzadori, M., Montebugnoli, L., \& De Sanctis, M. (2010). Patient morbidity and root coverage outcome after subepithelial connective tissue and de-epithelialized grafts: a comparative randomized-controlled clinical trial. J. Clin. Periodontol,37(8), 728-738.
12. de Mattos, P. M., Papalexiou, V., Tramontina, V. A., Kim, S. H., Luczyszyn, S. M., Bettega, P. V. C., \& Johann, A. B. R. (2019). Evaluation of 2 techniques of epithelial removal in subepithelial connective tissue graft surgery: a comparative histological study. J Periodontal Implant Sci, $50(1), 2-13$.

13. Lim, K. O., Kim, B. O., \& Lee, W. P. (2020). Technical Note on Root Coverage of Lower Anterior Teeth Using a Partially Deepithelialized Connective Tissue Graft (PE-CTG) Aided by a High-Speed Handpiece. Case Rep Dent, 2020.

14. Azar, E. L., Rojas, M. A., Patricia, M., \& Carranza, N. (2019). Histologic and Histomorphometric Analyses of De-epithelialized Free Gingival Graft in Humans. J. Periodontol, 39(2).

15. Chaushu, L., Rahmanov Gavrielov, M., Chaushu, G., \& Vered, M. (2020). Palatal Wound Healing with Primary Intention in a Rat Model-Histology and Immunohistomorphometry. Medicina, 56(4), 200.

16. McLeod, D. E., Reyes, E., \& Branch-Mays, G. (2009). Treatment of multiple areas of gingival recession using a simple harvesting technique for autogenous connective tissue graft. J. Periodontol., 80(10), 1680-1687.

17. Perotto, S., Romano, F., Cricenti, L., Gotti, S., \& Aimetti, M. (2017). Vascularization and Innervation of Connective Tissue Grafts in the Treatment of Gingival Recessions: A Histologic and Immunohistochemical Study. Int J Periodontics Restorative Dent, 37(4).

18. Hürzeler, M. B., \& Weng, D. (1999). A single-incision technique to harvest subepithelial connective tissue grafts from the palate. Int J Periodontics Restorative Dent, 19(3).

19. Bancroft, J. D., Layton, C., \& Suvarna, S. K. (2012): Bancroft's Theory and Practice of Histological Techniques, 7th ed., p. 187-214, Churchill Livingstone, Edinburgh, London.

20. Chan Y. (2003). Biostatistics102: Quantitative Data Parametric \& Non-parametric Tests. Singapore Med. J.; 44: 391-396.

21. Langer, L., \& Langer, B. (1993). The subepithelial connective tissue graft for treatment of gingival recession. Dent. Clin. N. Am., 37(2), 243-264.

22. Harris, R. J. (1992) The connective tissue and partial thickness double pedicle graft: a predictable method of obtaining root coverage. J. Periodontol, 63, 477-486.

23. Chambrone, L., \& Tatakis, D. N. (2015). Periodontal soft tissue root coverage procedures: a systematic review from the AAP Regeneration Workshop. J.periodontol, 86, S8-S51 . 
24. Petrungaro, P. S. (2001). Using platelet-rich plasma to accelerate soft tissue maturation in esthetic periodontal surgery. Compend. contin. educ. dent. (Jamesburg, NJ: 1995), 22(9), 729-32.

25. Harris, R. J. (2003) Histologic evaluation of connective tissue grafts in humans. Int $\mathrm{J}$ Periodontics Restorative Dent. 23, 575-583.

26. Mapara, M., Thomas, B. S., \& Bhat, K. M. (2012). Rabbit as an animal model for experimental research. Dent Res J (Isfahan), 9(1), 111.

27. Li, Y., Chen, S. K., Li, L., Qin, L., Wang, X. L., \& Lai, Y. X. (2015). Bone defect animal models for testing efficacy of bone substitute biomaterials. J. Orthop. Translat. , 3(3), 95-104.

28. Fritz, A. K., Amrein, I., \& Wolfer, D. P. (2017). Similar reliability and equivalent performance of female and male mice in the open field and water-maze place navigation task. Am. J. Med. Genet. (Vol. 175, No. 3, pp. 380-391).

29. Kremenak, N. W., \& Squier, C. A. (2002). Pioneers in Oral Biology: The Stories of Gottlieb, Kronfeld, Orban, Weinmann, and Sicher and Their Vienna-to-America Migrations. J Dent Educ , 66(1), 8-29.

30. Kumar, A., Sood, V., Masamatti, S. S., Triveni, M. G., Mehta, D. S., Khatri, M., \& Agarwal, V. (2013). Modified single incision technique to harvest subepithelial connective tissue graft. J Indian Soc Periodontol, 17(5), 676.

31. Fickl, S., Fischer, K. R., Jockel-Schneider, Y., Stappert, C. F., Schlagenhauf, U., \& Kebschull, M. (2014). Early wound healing and patient morbidity after single-incision vs. trap-door graft harvesting from the palate-a clinical study. Clin Oral Investig, 18(9), 2213-2219.

32. Bosco, A. F., \& Bosco, J. M. D. (2007). An Alternative
Technique to the Harvesting of a Connective Tissue Graft from a Thin Palate: Enhanced Wound Healing.J. Periodontol, 27(2).

33. Titford, M., \& Bowman, B. (2012). What may the future hold for histotechnologists. Lab Med 43(suppl_2), e5-e10.

34. Sanz-Martín, I., Rojo, E., Maldonado, E., Stroppa, G., Nart, J., \& Sanz, M. (2019). Structural and histological differences between connective tissue grafts harvested from the lateral palatal mucosa or from the tuberosity area. Clin Oral Investig, 23(2), 957-964.

35. Azar, E. L., Rojas, M. A., Mandalunis, P., Gualtieri, A., \& Carranza, N. (2019). Histological evaluation of subepithelial connective tissue grafts harvested by two different techniques. Preliminary study in humans. Acta Odontol Latinoam, 32(1), 10-16.

36. Zucchelli, G., \& Mounssif, I. (2015). Periodontal plastic surgery. Periodontol. 2000, 68(1), 333-368.

37. 37. Fletcher, P., Saito, H., Tarnow, D., \& Brown, M. (2011). Cyst in alveolar mucosa adjacent to a dental implant following connective tissue grafting for ridge augmentation. Clin Adv Periodontics, 1(1), 34-39.

38. Bruno, J. F. (1994). Connective tissue graft technique assuring wide root coverage. J. Periodontol, 14(2).

39. Ciftci, H., TÜRK, M., TAMER, U., Karahan, S., \& Menemen, Y.(2013). Silver nanoparticles: cytotoxic, apoptotic, and necrotic effects on MCF-7 cells. Turk.J. Biol., 37(5), 573-581.

40. Bertl, K., Pifl, M., Hirtler, L., Rendl, B., Nürnberger, S., Stavropoulos, A., \& Ulm, C. (2015). Relative composition of fibrous connective and fatty/glandular tissue in connective tissue grafts depends on the harvesting technique but not the donor site of the hard palate. J. Periodontol, 86(12), 1331-1339. 